\title{
Proposal of early retreatment with iloprost in partially responsive patients with bone marrow edema syndrome: a case report
}

\author{
Uso di iloprost nella "bone marrow edema syndrome": \\ proposta di ritrattamento precoce nei pazienti parzialmente responder. \\ Case report
}

\author{
Simone Meini ${ }^{a, *}$, Grazia Panigada ${ }^{b}$ \\ a Internal Medicine Unit, Santa Maria Maddalena Hospital of Volterra, ASL Pisa (Italy) \\ ${ }^{\mathrm{b}}$ Internal Medicine Unit, Santi Cosma e Damiano Hospital of Pescia, ASL Pistoia (Italy)
}

Received 5 March 2012; accepted 9 May 2012

Available online 13 June 2012

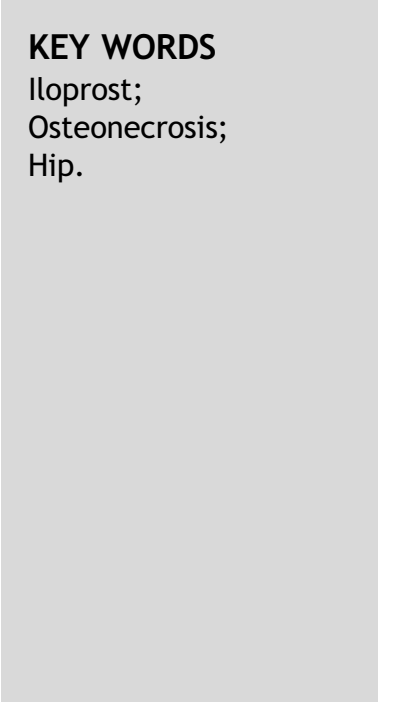

\begin{abstract}
Summary
Background: Avascular Necrosis (AVN) is defined as the cellular death of bone components due to an alteration of the blood supply, resulting in Edema of the Bone Marrow (BME), structural collapse and bone destruction. In advanced stages, AVN requires surgery. One emerging medical treatment for supporting osseous perfusion is the administration of iloprost.

Materials and methods: A 38-year-old woman presented with severe BME of the left hip (primary), persisting for 6 weeks. She was treated with iloprost iv at $2 \mathrm{ng} / \mathrm{kg} / \mathrm{min}$ for 6 hours/day for 5 days, and after 4 weeks, the treatment was repeated at $1.5 \mathrm{ng} / \mathrm{kg} / \mathrm{min}$ for 6 hours for 5 days because she exhibited only a partial response to the first treatment. Complete remission was obtained, documented clinically and on Magnetic Resonance Imaging (MRI). Her Harris Hip Score (HHS) increased from 29.90 to 97 . No significant adverse events related to iloprost were registered. No surgical procedures were necessary.

Conclusions: In most cases, iloprost is administered in a single cycle of treatment over 5 days at 1-2 $\mathrm{ng} / \mathrm{kg} / \mathrm{min}$ for 6 hours/day, but no research has investigated the effectiveness of early retreatment after the first cycle results in only a partially response. Only a few studies examining small numbers of patients have evaluated iloprost in AVN/BME, preferring, in most cases, the dose of $1 \mathrm{ng} / \mathrm{kg} / \mathrm{min}$ and obtaining clinical improvement both in BME and in AVN in times comparable to surgical core decompression. This case report demonstrates the safety and
\end{abstract}

\footnotetext{
* Corresponding author: Unità Operativa di Medicina Interna, Ospedale Santa Maria Maddalena, Borgo San Lazzero 5-56048 Volterra (PI), Italy. E-mail: simonemeini1@virgilio.it (S. Meini).
} 
effectiveness of early repetition of the maximal dose of iloprost before BME evolves into AVN, as well as in cases initially appearing serious and requiring surgical procedures.

(c) 2012 Elsevier Srl. All rights reserved.

\section{Introduction}

Avascular Necrosis (AVN) is defined as the cellular death of bone components due to an alteration of the blood supply, resulting in Edema of the Bone Marrow (BME), structural collapse and bone destruction, and usually involving epiphysis of the long bones with a terminal blood supply. Various conditions can cause AVN; however, almost half of the patients diagnosed with AVN present with none of these conditions. This type of AVN is termed primary or idiopathic $\mathrm{AVN}$. All of the other forms of this disease are secondary, associated with an underlying condition (such as trauma, radiation exposure, hemoglobinopathies, polycythemia, hypercoagulable states, hyperparathyroidism, infections, neoplasms, systemic lupus erythematosus). One of the most common causes of secondary avascular necrosis is prolonged systemic steroid use at high doses for extended periods of up to 3 months or longer. Most often, BME/AVN occurs during the fourth or fifth decade of life and in men (male-to-female ratio of $8: 1$ ). The incidence of $A V N$ is increasing, and the causes include greater use of exogenous steroids and increases in trauma. AVN can be asymptomatic, but pain and limitations in joint movements are usually the presenting symptoms; $55 \%$ of cases are bilateral. Advanced AVN causes joint deformity and loss of function, nerve compression and muscle wasting. BME can occur both in isolation and in association with necrosis, but no study has shown whether each condition responds to the same treatments. In the advanced stages, AVN requires surgery. In the early stages (precollapse), core decompression, with or without a bone graft, is considered the most appropriate treatment. Another appropriate procedure is osteotomy. In later stages, which are characterized by collapse and femoral head deformity with secondary osteoarthritis, total hip arthroplasty is appropriate. Early diagnosis and prompt intervention can delay the need for joint replacement.

The medical management of BME/AVN primarily depends on the stage, location and severity of the disease, as well as the patient's age and general health. Up to now, no medical treatment has proved completely effective in preventing or arresting the disease. Various efforts have been undertaken to enhance the healing of osseous defects before collapse, including pharmacologic measures (bisphosphonates, statins), immobilization, electrical stimulation, shock wave therapy and electromagnetic field therapy [1-3].

One emerging treatment option to support osseous perfusion in BME/AVN is the administration of the stable prostacyclin analogue iloprost, which exerts several effects on vascular regulation, such as vasodilation and inhibition of platelet aggregation. Iloprost is also able to regulate the gene expression patterns of vascular cells via direct (intranuclear PPAR receptor-mediated) and indirect (IP receptorCAMP-PKA-mediated) signaling pathways. For iloprost, we can hypothesize that a large number of pleiotropic effects, aside from its vasodilatory and anti-platelet effects, influence $B M E / A V N$ pathogenesis, including the regulation of the proliferation of smooth muscular cells and modulation of their phenotypic pattern; anti-inflammatory effects (e.g., the reduction of TNF- $\alpha$ production); the reduction of vascular permeability in inflammation; the reduction of $\alpha M \beta 2$-integrin (in neutrophils and monocytes) and ICAM-1 (in the endothelium); the reduction of ischemia/reperfusion injury; the modulation of ischemic preconditioning; neoangiogenesis (through VEGF production); and an increase in the number of circulating endothelial progenitor cells [4-7]. Iloprost also binds to EP1 and EP4 receptors: EP4 receptors are implicated in bone remodeling, through the modulation of osteoclastic activity, and in the differentiation process, while EP1 receptors are implicated in the growth of bone $[8,9]$. It is therefore possible to theorize that an adjunctive effect is mediated via these pathways.

The main indication for iloprost treatment, supported by evidence from the literature, is Critical Limb Ischemia (CLI) unsuitable for revascularization. Iloprost treatment is commonly administered at $0.5-2 \mathrm{ng} / \mathrm{kg} / \mathrm{min}$ for 6 hours/day over 2-4 weeks, but more intensive regimens are also used (16 hours/day over 7 days) [7]. Iloprost is also used for the chronic treatment of systemic sclerosis.

In the literature, sporadic experiences with off-label iloprost use in BME/AVN have been conducted with single cycles of 5 days at $1-2 \mathrm{ng} / \mathrm{kg} / \mathrm{min}$ (especially the lower dose) for 6 hours each day; no researchers have investigated the effectiveness of early retreatment after the first cycle results in a only partial response.

The aim of this work was to demonstrate the effectiveness, tolerability and safety of an early retreatment with iloprost, administered at the maximal dose $(1.5-2 \mathrm{ng} / \mathrm{kg} / \mathrm{min})$ only a few weeks after an analogous first cycle because of an incomplete response. Thus, this work proposes, for the first time, an administration regimen characterized by early repetition in cases of partial or delayed response.

\section{Case report}

A 38-year-old woman presented to us with severe pain at rest in her left hip, persisting for 6 weeks. Both active and passive joint movement restrictions were observable. On a visual analogue scale of pain, scored from 0 to 10 , she reported a score of 8 , scarcely responding to analgesics (tramadol and ibuprofen) prescribed since the initial symptoms. Her Harris Hip Score (HHS) was 29.90.

She denied previous trauma and any drug use (only contraceptive therapy, which was immediately stopped); she had never smoked and drunk alcohol. The laboratory data showed no alterations of inflammatory indices (erythrocyte sedimentation rate, C-reactive protein), hemochrome, alkaline phosphatase, or renal or liver function; no alterations were found in coagulation parameters, such as D-dimer, PT, PTT, APC resistance and Leiden's factor V, G202010A prothrombin 

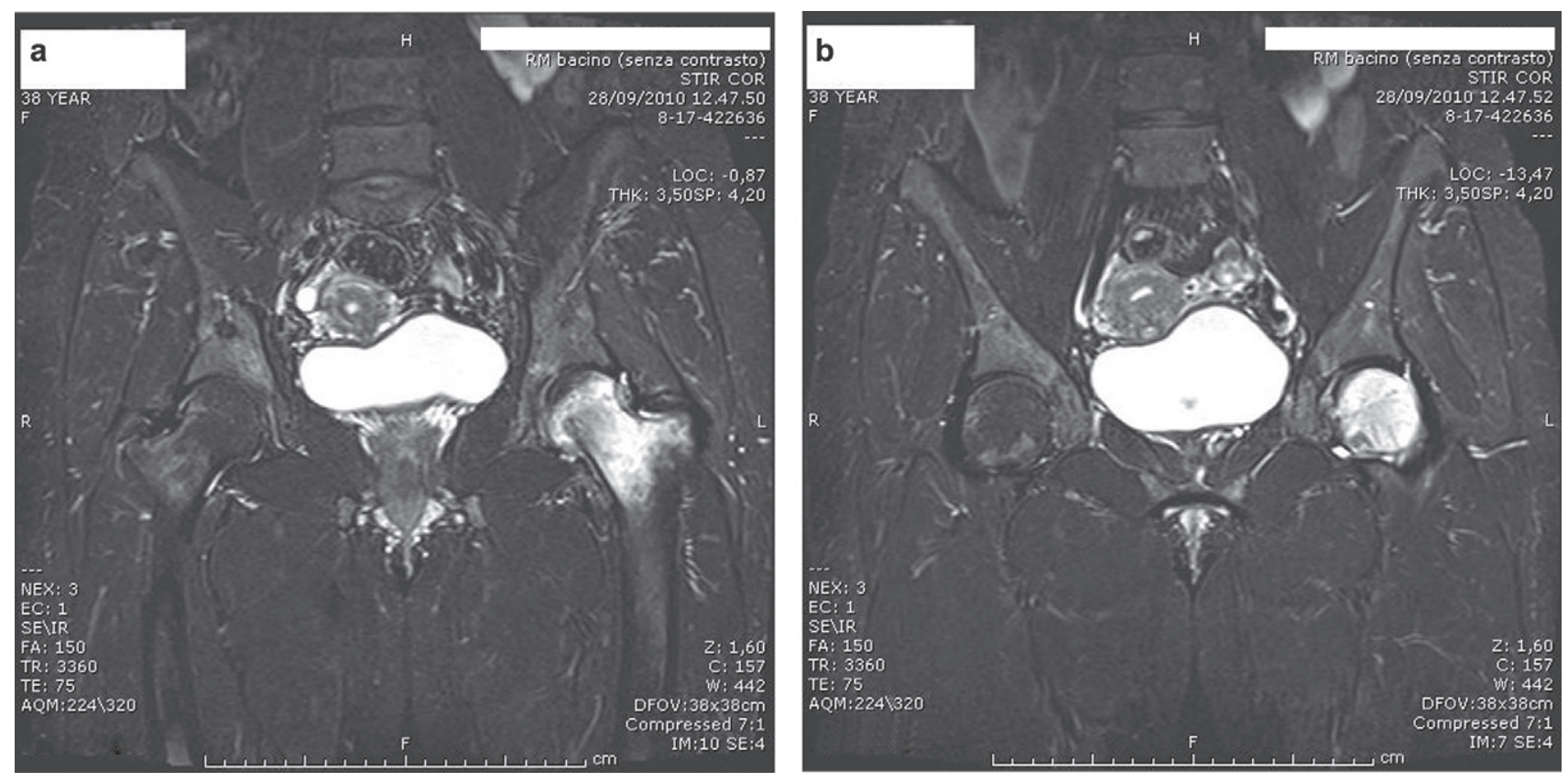

Figure 1a,b MR imaging (STIR sequences) of the hips before iloprost treatment.

mutation, C-coagulative protein, S-coagulative protein, or antithrombin, or in autoimmunity testing (ANA, ENA, ANCA, anti-C(P). Homocysteine levels were in the normal range.

Two weeks earlier, she has undergone Magnetic Resonance Imaging (MRI) (fig. 1a,b), which showed an important signal alteration of adipocyte cellular tissue in the left femoral head and neck, expressed as significant T2w and STIR hyperintensity, correlated with an edematous infiltration phenomenon. No remodeling process or deformation of the femoral head was present. Concomitant intra-articular fluid effusion was described.

She was initially treated by proposing rest, analgesics and Low-Molecular-Weight Heparin (LMWH, enoxaparin 4000 IU sc od, for 3 weeks), but after 2 weeks without any improvement, she came to our attention. After providing informed consent, she received intravenous iloprost infusions with a peristaltic infusion pump, after dilution ( $50 \mu \mathrm{g}$ of iloprost in $250 \mathrm{~mL}$ of saline), for 6 hours/day over 5 days (total of $50 \mu \mathrm{g} /$ day). The infusion began with a dose of $0.5 \mathrm{ng} / \mathrm{kg} / \mathrm{min}$ and was increased a further $0.5 \mathrm{ng} / \mathrm{kg} / \mathrm{min}$ every $30 \mathrm{~min}$ up to the maximum dose $(2 \mathrm{ng} / \mathrm{kg} / \mathrm{min})$. On the second day, the infusion was begun at the maximal dose. So as not to affect the final estimation of the effects of iloprost, no new drugs were allowed during treatment, the analgesics was stopped, and only LMWH was maintained. Iloprost was administered without any significant major reactions. During iloprost treatment, the patient reported significant reductions in pain and joint impairment beginning on the third day.

Four weeks after treatment, MRI was repeated (fig. 2a,b), evincing a significant improvement, consisting of a reduction in the signal alteration previously described and the disappearance of intra-articular effusion. Both the active and passive joint movement restrictions greatly improved, and the patient reported a VAS pain score of 2 ; her HHS also significantly improved, resulting in a score of 85 .
Supported by this important, but incomplete, clinical and instrumental improvement, we decided to retreat our patient early, at 4 weeks after the first cycle, preferring a dose of $1.5 \mathrm{ng} / \mathrm{kg} / \mathrm{min}$ for 6 hours/day over another 5 days, to limit mild collateral effects, such as nausea and headache. During and in the days after this treatment, the pain completely disappeared (0), the HHS was assessed at 97, and the patient reported that all of her symptoms had completely disappeared.

Four weeks after the second treatment, MRI was repeated (fig. 3a,b), showing further improvement of the imaging data, with a reduction in the edema of the left femur. After a further 12 weeks, MRI (fig. 4a,b) showed complete remission.

\section{Discussion}

In the literature, relatively few cases of iloprost use in patients with BME/AVN have been reported. Jäger et al. $[10,11]$ showed that iloprost could contribute to the relief of pain and can improve joint function only in the early stages, while advanced-stage AVN did not benefit from it.

Disch et al. [12] treated patients for isolated edema and for necrosis of the proximal femur and found that iloprost allowed, in both circumstances, significant improvement in HHS, range of movement, extent of edema as measured by MRI, pain and patient satisfaction. Meizer et al. [13] administered $20-50 \mu \mathrm{g}$ of iloprost over 6 hours on 5 consecutive days in 27 patients affected by BME of the femoral head and found better outcomes in terms of pain reduction and MRI patterns. Previously, the same authors [14] observed one of the most important case series of BME treated with iloprost, infused with 20,25 or $50 \mu \mathrm{g}$, given over 6 hours on 5 consecutive days; 4 months after the therapy, pain at rest had 

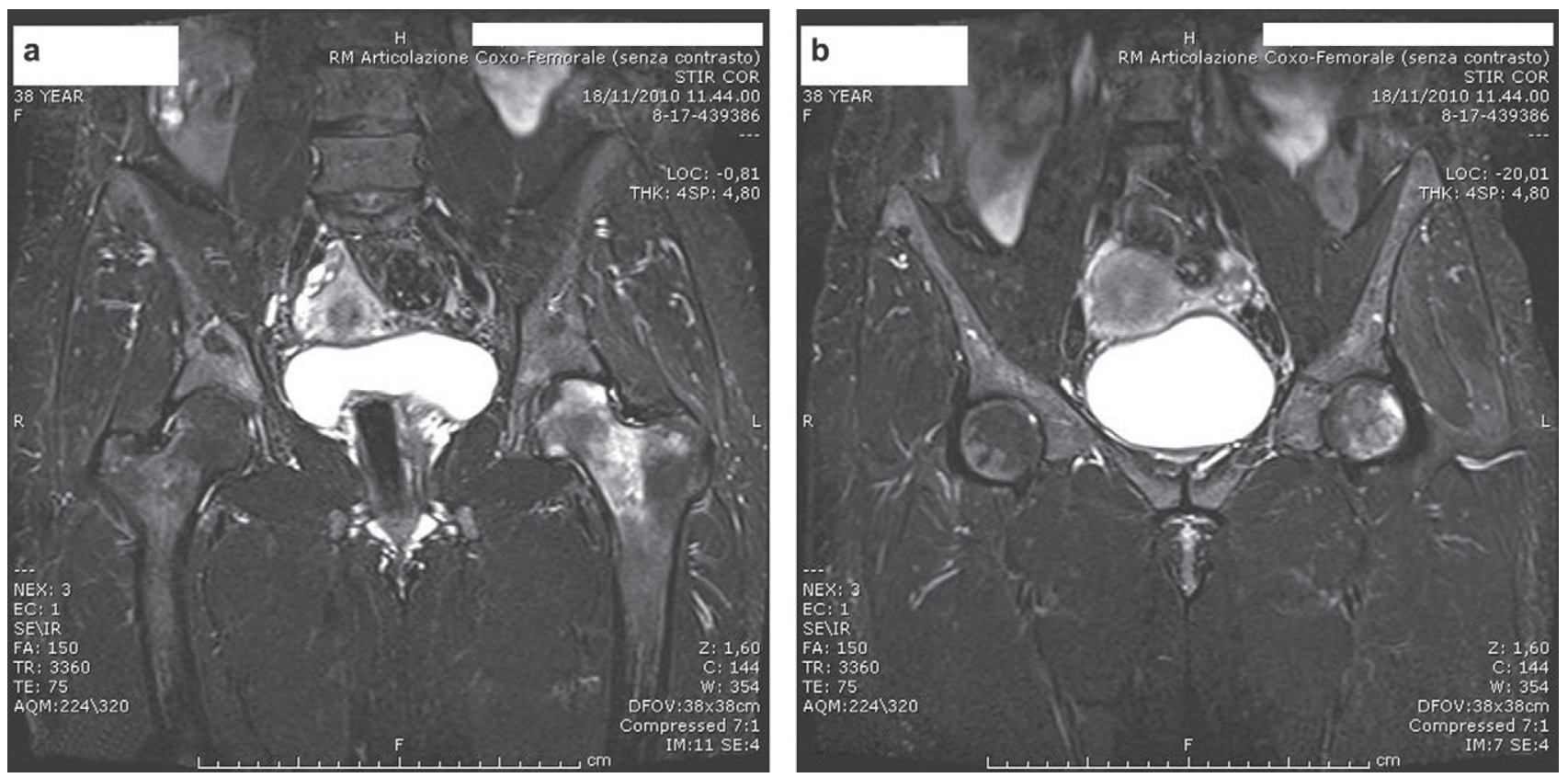

Figure 2a,b MR imaging (STIR sequences) of the hips 4 weeks after the first iloprost treatment.
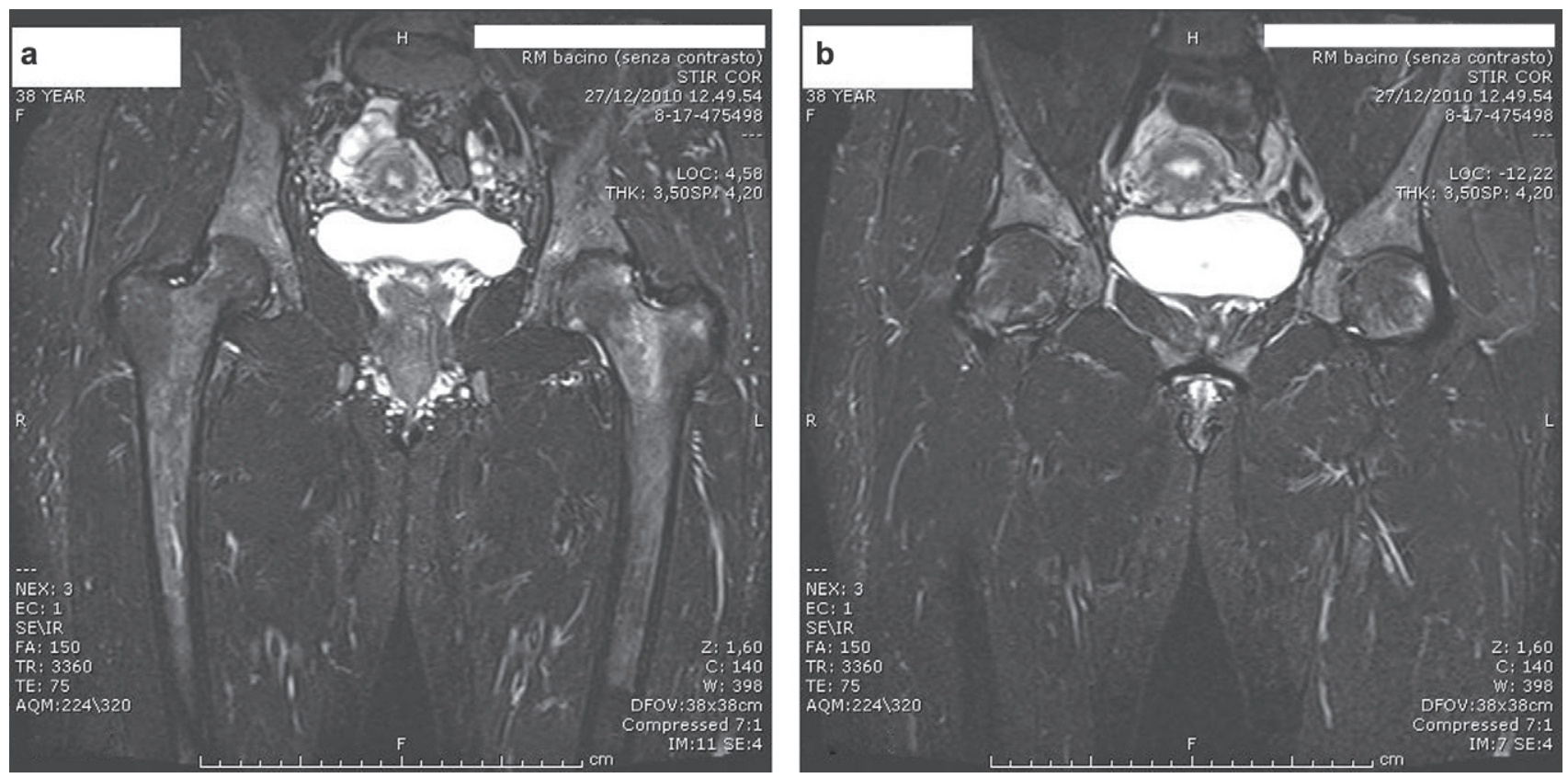

Figure 3a,b MR imaging (STIR sequences) of the hips 4 weeks after the second iloprost treatment.

diminished by $73 \%$, pain under stress had decreased by $59 \%$, and $65 \%$ of the patients had significant reductions in BME size or complete normalization on MRI. The side effects were significantly reduced at daily dose of $20 \mu \mathrm{g}$, without impairment of the therapeutic effect.

Aigner et al. [15] compared instead the efficacy of iloprost (20 $\mu \mathrm{g}$ daily) with surgical core decompression in BME of the hip and found that iloprost can achieve equal or better results; in both groups, the high level of clinical recovery was maintained after 12 months. Aigner et al. [16] also demonstrated that iloprost is a safe and effective treatment for pregnant women with BME of femoral head, avoiding the need for surgical intervention; therapy could begin some days after parturition, with a brief discontinuation during breastfeeding. Moreover, iloprost administration represents an interesting option for BME in children, with comparable safety and efficacy effects $[17,18]$.

Finally, iloprost administered intravenously over 5 days represents an effective treatment in post-transplant distal limb syndrome, a type of BME representing a benign but disabling complication in the first year after renal transplantation [19]. 

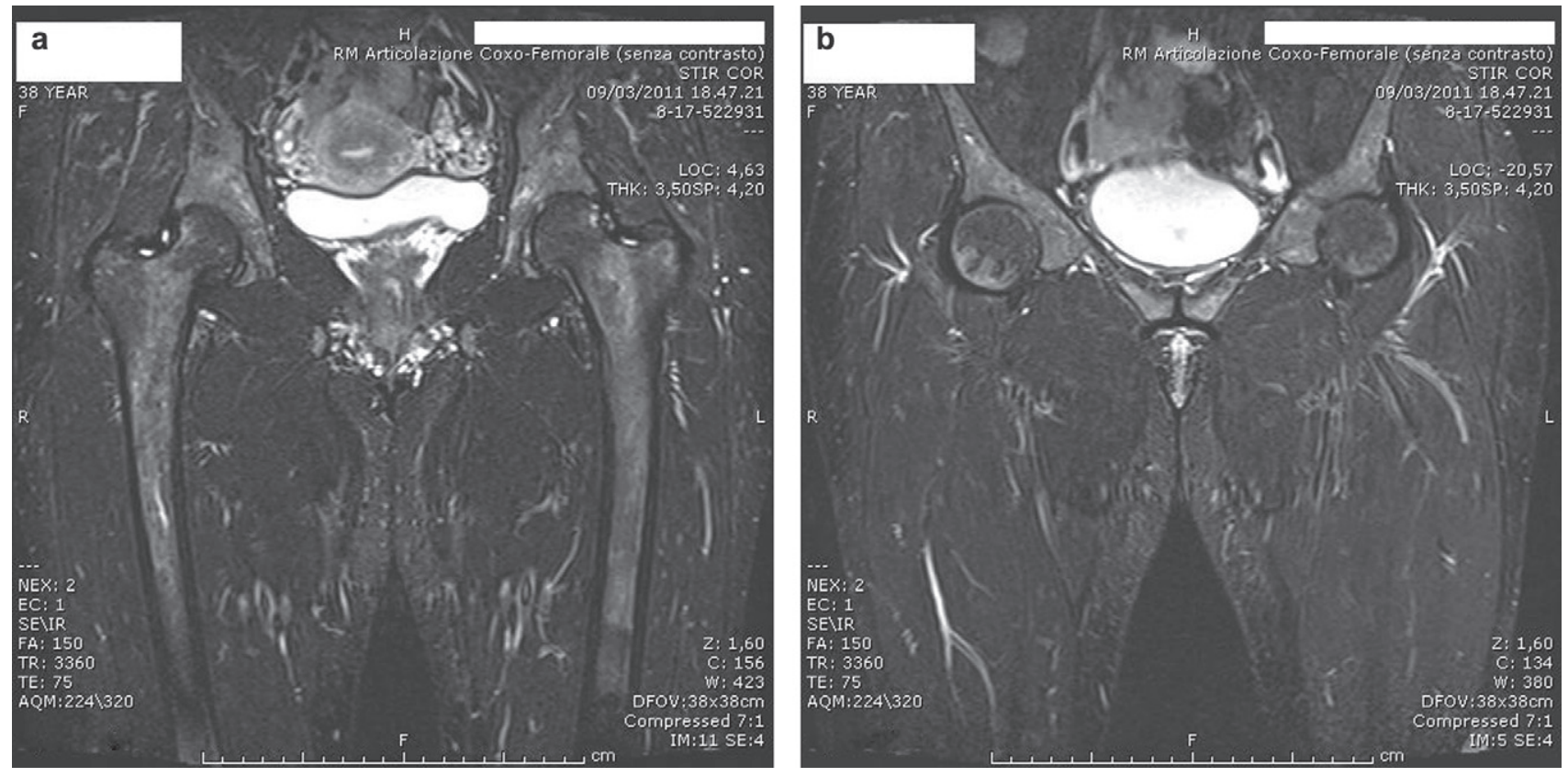

Figure 4a,b MR imaging (STIR sequences) of the hips 16 weeks after the second iloprost treatment.

In the above-reported cases, relatively few patients affected by BME/AVN were treated, until now, with iloprost, in comparison to the experience gained over the years with traditional surgery. In most of the few cases described in the literature, iloprost was not administered at the full dose (compared to the usual regimen validated for critical limb ischemia and systemic sclerosis patients) of $2 \mathrm{ng} / \mathrm{kg} / \mathrm{min}$ (equal to almost $50 \mu \mathrm{g}$ daily), perhaps due to unjustified alarm concerning the risk of severe adverse cardiovascular events and collateral effects deriving from off-label administration. In most cases, iloprost was administered at the dose of $1 \mathrm{ng} / \mathrm{kg} / \mathrm{min}$ ( $\approx 25 \mu \mathrm{g}$ daily) and only once. No experience with early retreatment had been reported until now.

Personal experience with the extensive and safe administration of iloprost in critical limb ischemia patients, most of which represent complex cases because they are also affected by severe coronary and cerebrovascular disease, and the previous proposal and validation of new treatment schemes [7] allowed us to treat our patient with the full dose of the drug without any fear. In addition, experimenting with early repetition, to our knowledge, had previously never been described without observing adverse events, even if female patients are notoriously less tolerant to the collateral effects of iloprost infusion.

The clinical response in our patient was excellent, so we propose the possibility of early repetition of iloprost as a safe and effective pharmacological option in severe cases of BME that are refractory or that have exhibited a partial response to the first treatment regimen, as well as in cases at high risk for evolution of $\mathrm{AVN}$ and consequently requiring surgical procedures. The main purpose of this case report was to show that this medical possibility is worthy of consideration before BME evolves into AVN, without preconceptions or unjustified alarm concerning adverse collateral events related to iloprost administration.
In conclusion, iloprost can be administered intravenously at $1-2 \mathrm{ng} / \mathrm{kg} / \mathrm{min}$ for 6 hours/day for a period of 5 days, the dose of $2 \mathrm{ng} / \mathrm{kg} / \mathrm{min}$ is as safe as $1 \mathrm{ng} / \mathrm{kg} / \mathrm{min}$, and the treatment can be repeated early in cases of only partial response to the first treatment.

Despite the positive results in the literature regarding the efficacy of iloprost use in BME/AVN, there is, as of now, no conclusive evidence based on well-conducted, high-quality, randomized, double-blinded trials; the low prevalence of this condition represents the main problem in realizing such trials. It is likely that only knowledge of this possibility for medical treatment on the part of a larger number of physicians, internists, angiologists and orthopedic surgeons will result, in the future, in the realization of trials of adequate clinical burden.

\section{Conflict of interest statement}

The authors have no conflict of interest to disclose.

\section{Ethical review board committee statement}

The author states that the study was approved by the ethics committee and therefore was performed in accordance with the ethical standards of the 1964 Declaration of Helsinki. The study was carried out in accordance with the relevant regulations of the US Health Insurance Portability and Accountability Act (HIPAA). Details that might disclose the identity of the subject under study were omitted. The patient investigated in this report gave informed consent to treatment and to the presentation of the results in published form. Work performed at Santa Maria Maddalena of Volterra Hospital, ASL Pisa, Italy. 


\section{References}

[1] Mont MA, Jones LC, Seyler TM, Marulanda GA, Saleh KJ, Delanois RE. New treatment approaches for osteonecrosis of the femoral head: an overview. Instr Course Lect 2007;56: 197-212.

[2] Kibbi L, Touma Z, Khoury N, Arayssi T. Oral bisphosphonates in treatment of transient osteoporosis. Clin Rheumatol 2008; 27(4):529-32.

[3] La Montagna G, Malesci D, Tirri R, Valentini G. Successful neridronate therapy in transient osteoporosis of the hip. Clin Rheumatol 2005;24(1):67-9.

[4] Mazzone A, Faggioli P, Cusa C, Stefanin C, Rondena M, Morelli B. Effects of iloprost on adhesion molecules and $F 1+2$ in peripheral ischemia. Eur J Clin Invest 2002;32(12):882-8.

[5] Mazzone A, Mazzucchelli I, Fossati G, Gritti D, Girola S, Canale $C$, et al. Iloprost effects on phagocytes in patients suffering from ischaemic diseases: in vivo evidence for downregulation of alpha $M$ beta 2 integrin. Eur $\mathrm{J}$ Clin Invest 1996;26(10):860-6.

[6] Di Renzo M, Pieragalli D, Meini S, De Franco V, Pompella G, Auteri A, et al. Iloprost treatment reduces TNF-alpha production and TNF-RII expression in critical limb ischemia patients without affecting IL6. Prostaglandins Leukot Essent Fatty Acids 2005;73(5):405-10.

[7] Meini S, De Franco V, Auteri A, Setacci C, Di Renzo M, Pieragalli D. Short-term and long-term effects of one-week treatment with intravenous iloprost in critical limb ischemia patients (LericheFontaine stage III and IV). Int Angiol 2005;24(1):64-9.

[8] Narumiya S, Sugimoto Y, Ushikubi F. Prostanoid receptors: structures, properties, and functions. Physiol Rev 1999;79(4): 1193-226.

[9] Suda M, Tanaka K, Natsui K, Usui T, Tanaka I, Fukushima M, et al. Prostaglandin E receptor subtypes in mouse osteoblastic cell line. Endocrinology 1996;137(5):1698-705.

[10] Jäger M, Tillmann FP, Thornhill TS, Mahmoudi M, Blondin D, Hetzel GR, et al. Rationale for prostaglandin $\mathrm{I} 2$ in bone marrow oedema-from theory to application. Arthritis Res Ther 2008; 10(5):R120.

[11] Jäger $M$, Zilkens C, Bittersohl B, Matheney T, Kozina G, Blondin $D$, et al. Efficiency of iloprost treatment for osseous malperfusion. Int Orthop 2011;35(5):761-5.

[12] Disch AC, Matziolis G, Perka C. The management of necrosisassociated and idiopathic bone-marrow oedema of the proximal femur by intravenous iloprost. J Bone Joint Surg Br 2005; 87(4):560-4.

[13] Meizer R, Meraner D, Meizer E, Radda C, Landsiedl F, Aigner N. Outcome of painful bone marrow edema of the femoral head following treatment with parenteral iloprost. Indian J Orthop 2009;43(1):36-9.

[14] Meizer R, Radda C, Stolz G, Kotsaris S, Petje G, Krasny C, et al. MRI-controlled analysis of 104 patients with painful bone marrow edema in different joint localizations treated with the prostacyclin analogue iloprost. Wien Klin Wochenschr 2005;117(7-8):278-86.

[15] Aigner N, Petje G, Schneider W, Meizer R, Wlk M, Kotsaris S, et al. Bone marrow edema syndrome of the femoral head: treatment with the prostacyclin analogue iloprost vs. core decompression: an MRI-controlled study. Wien Klin Wochenschr 2005;117(4):130-5.

[16] Aigner N, Meizer R, Meraner D, Becker S, Meizer E, Landsiedl $F$. Bone marrow edema syndrome in postpartal women: treatment with iloprost. Orthop Clin North Am 2009;40(2):241-7.

[17] Aigner N, Petje G, Schneider W, Krasny C, Grill F, Landsiedl F. Juvenile bone-marrow oedema of the acetabulum treated by iloprost. J Bone Joint Surg Br 2002;84(7):1050-2.

[18] Petje G, Radler C, Aigner N, Manner H, Kriegs-Au G, Grill F. Pharmacological management of aseptic osteonecrosis in children. Expert Opin Pharmacother 2004;5(7):1455-62.

[19] Tillmann FP, Jäger M, Blondin D, Schooldermann D, Voiculescu A, Sucker C, et al. Intravenous iloprost: a new therapeutic option for patients with post-transplant distal limb syndrome (PTDLS). Am J Transplant 2007;7(3):667-71. 